\title{
Residual Stress in Stainless Steels after Surface Grinding and its Effect on Chloride Induced SCC
}

\author{
Nian Zhou, a ", Ru Lin Peng ${ }^{2, b}$, Rachel Pettersson ${ }^{3, c}$ and Mikael Schönning ${ }^{4, d}$ \\ ${ }^{1}$ Department of Material Science, Dalarna University, SE-79188 Falun, and KTH, SE-10044 \\ Stockholm, Sweden \\ ${ }^{2}$ Department of Management and Engineering, Linköping University, SE-58183 Linköping, \\ Sweden \\ 3Jernkontoret, SE-11187 Stockholm, and KTH, SE-10044 Stockholm, Sweden \\ ${ }^{4}$ Corrosion Department, Avesta Research Center - Outokumpu Stainless AB, SE-77422 Avesta, \\ Sweden \\ a, nzh@du.se, b, ru.peng@liu.se, c, rachel.pettersson@jernkontoret.se, \\ d, mikael.schonning@outokumpu.com
}

\section{Keywords: Grinding, Stainless Steel, Residual Stress, Stress Corrosion Cracking}

\begin{abstract}
The induced residual stresses in stainless steels as a consequence of surface grinding as well as their influence on the chloride induced stress corrosion cracking (SCC) susceptibility have been investigated. Three types of materials were studied: 304L austenitic stainless steel, 4509 ferritic stainless steel and 2304 duplex stainless steel. Surface grinding using 60\# and 180\# grit size abrasives was performed for each material. Residual stress depth profiles were measured using X-ray diffraction. The susceptibility to stress corrosion cracking was evaluated in boiling $\mathrm{MgCl}_{2}$ according to ASTM G36. Specimens were exposed without applying any external loading to evaluate the risk for SCC caused solely by residual stresses. Induced residual stresses and corrosion behavior were compared between the austenitic, ferritic and duplex stainless steels to elucidate the role of the duplex structure. For all materials, the grinding operation generated tensile residual stresses in the surface along the grinding direction but compressive residual stresses perpendicular to the grinding direction. In the subsurface region, compressive stresses in both directions were present. Microcracks initiated due to high grinding-induced tensile residual stresses in the surface layer were observed in austenitic 304L and duplex 2304, but not in the ferritic 4509. The surface residual stresses decreased significantly after exposure for all specimens.
\end{abstract}

\section{Introduction}

Stainless steels are widely used in a variety of applications due to their combination of good mechanical properties and high corrosion resistance. There are a large number of stainless steel grades with different chemical compositions and microstructures. Since the microstructure has a decisive effect on the properties, stainless steels are often categorized by the microstructure, for example austenitic and ferritic stainless steels; different categories are suited for different applications [1].

Stress corrosion cracking (SCC) occurs under the simultaneous interaction of three factors: a corrosive environment, a susceptible material and the presence of tensile stresses [2]. For stainless steels, the chloride ion, which exists in many environments, is unfortunately found to make them prone to stress corrosion cracking. The stress corrosion cracking behavior of stainless steels has been widely investigated during the last decades. Experimental results show austenitic stainless steels are susceptible to SCC while ferritic grades are quite resistant [3]. Due to the combination of austenitic and ferritic structures, duplex stainless steels generally have higher Cl-SCC resistance compared to the austenitic grades, although this may depend on the actual testing conditions [4]. In addition to 
microstructural effects, residual stresses also have a significant impact. For example, laser peening of ANSI 304 austenitic stainless steel has been demonstrated to improve the SCC resistance; the introduced high level compressive residual stress and grain refinement were proposed as the two main factors [5]. High surface tensile residual stresses introduced by milling as well as a detrimental surface profile have been reported to generate branched cracks on 316Ti austenitic stainless steel surface after exposure in boiling $\mathrm{MgCl}_{2}$ solution [6].

Grinding is an important and widely used surface finishing process when fabricating stainless steels. During grinding, both plastic deformation and heating occur in the surface layer, which in turn change the residual stress state in the material. However, little research has been performed to evaluate the role of pure residual stress in the risk for SCC. The aim of this study is to increase the understanding of residual stresses induced by surface grinding of stainless steels as well as their role in crack initiation and propagation. In addition, the role of the ferritic and austenitic microstructure in a duplex stainless steel has also been investigated.

\section{Experimental work}

Three grades of stainless steels, austenitic 304L, ferritic 4509 and duplex 2304, were investigated in this study. The as-delivered materials had been solution annealed at $1100^{\circ} \mathrm{C}$, quenched, pickled and roll leveled. The materials were supplied with $2 \mathrm{~B}$ surface finish and as test coupons of $400 \mathrm{~mm} \times 150 \mathrm{~mm} \times 2 \mathrm{~mm}$ in dimensions. The chemical compositions and measured mechanical properties perpendicular to the rolling direction at room temperature are given in Table 1.

Table 1 Chemical compositions (wt.\%) and mechanical properties, measured perpendicular to the rolling direction at room temperature, of stainless steels investigated

\begin{tabular}{cccccccccccccccccc}
\hline Grade & $\mathrm{C}$ & $\mathrm{Si}$ & $\mathrm{Mn}$ & $\mathrm{P}$ & $\mathrm{S}$ & $\mathrm{Cr}$ & $\mathrm{Ni}$ & $\mathrm{Mo}$ & $\mathrm{Nb}$ & $\mathrm{N}$ & $\mathrm{Cu}$ & $\mathrm{Co}$ & $\mathrm{Ti}$ & $\mathrm{Rp} 0.2(\mathrm{MPa})$ & $\begin{array}{c}\text { Rm } \\
(\mathrm{MPa})\end{array}$ & $\begin{array}{c}\text { Elongation } \\
(\%)\end{array}$ & $\begin{array}{c}\text { Hardness } \\
(\mathrm{HB})\end{array}$ \\
\hline $304 \mathrm{~L}$ & 0.02 & 0.32 & 1.55 & 0.03 & 0 & 18.2 & 8.11 & - & 0.01 & 0.07 & 0.31 & 0.16 & - & 230 & 642 & 54 & 170 \\
4509 & 0.01 & 0.48 & 0.46 & 0.03 & 0 & 17.9 & 0.2 & - & 0.37 & - & - & - & 0.13 & 345 & 462 & 32 & 175 \\
2304 & 0.02 & 0.39 & 1.48 & 0.03 & 0 & 23.4 & 4.84 & 0.36 & - & 0.13 & 0.22 & - & 0.01 & 590 & 739 & 30 & 228 \\
\hline
\end{tabular}

The grinding operations were conducted on a Chevalier FSG-2A618 grinding machine using grinding belts with conventional aluminum oxide grit. The detailed grinding set-up is described in [1]. All the grinding operations were performed along the rolling direction of the material. A fixed grinding speed $\mathrm{v}_{\mathrm{s}}=23 \mathrm{~m} / \mathrm{s}$, a fixed feed rate $\mathrm{v}_{\mathrm{w}}=8 \mathrm{~m} / \mathrm{min}$ and a fixed motor power of $600 \mathrm{~W}$ were used. Grinding was first performed using 60\# grit size abrasive to remove the as-delivered material surface, and then followed by grinding with new $60 \#$ and $180 \#$ grit size abrasives respectively to get the final surface finish for each material. No grinding lubricant was used during the operation.

The influence of residual stress from surface grinding on chloride induced stress corrosion cracking susceptibility was investigated without applying external loading. Two $30 \mathrm{~mm}$ by $30 \mathrm{~mm}$ square-sized specimens were cut out from each test coupon with different grinding conditions. All specimens were exposed for $20 \mathrm{~h}$ in boiling $\mathrm{MgCl}_{2}$ solution at $155^{\circ} \mathrm{C} \pm 1^{\circ} \mathrm{C}$ according to ASTM G36. Detailed corrosion procedures are described in [2].

The in-depth residual stress profiles were measured by X-ray diffraction for all the ground specimens. $\mathrm{Cr}-\mathrm{K}_{\alpha}$ radiation was used; residual stresses were determined from the measured diffraction peak at $2 \theta \sim 128^{\circ}$ for the $\{220\}$ lattice planes of the austenitic phase and at $2 \theta \sim 154^{\circ}$ for the $\{211\}$ lattice planes of the ferritic phase respectively. Residual stresses were calculated based on the $\sin ^{2} \psi$ method [3]. Controlled electrolytic polishing was used to remove the material and measure the in-depth profiles; no correction was made for possible stress relaxation due to polishing. Surface stresses of all types of specimens were also measured after corrosion tests using the same method. The surface morphology after exposure was investigated using a FEG-SEM Zeiss Ultra 55 scanning electron microscopy (SEM). Both SEM and ECCI (electron channeling contrast imaging, Hitachi FEG-SEM SU-70) were used for examination of cross-sections after corrosion testing. 


\section{Results and Discussion}

The in-depth residual stress profiles parallel $\left(\sigma_{\|}\right)$and perpendicular $\left(\sigma_{\perp}\right)$ to the grinding directions of all three types of materials ground by both 60\# and 180\# abrasive grit size as final surface finish are presented in Figure 1. For the duplex 2304, the results are presented as phase stresses and macrostresses. Phase stresses are residual stresses measured in the austenitic phase (FCC), $\sigma^{\gamma}$, and ferritic phase $(\mathrm{BCC}), \sigma^{\alpha}$, respectively. The macro-stress $\left(\sigma^{\mathrm{M}}\right)$ is the homogeneous residual stress on a macroscopic scale along at least one direction [3] and is calculated according to the equation: $\sigma^{\mathrm{M}}=$ $\mathrm{V}^{\gamma} \sigma^{\gamma}+\left(1-\mathrm{V}^{\gamma}\right) \sigma^{\alpha}$ (where $\mathrm{V}^{\gamma}$ is the volume fraction of the austenitic phase). As shown in Figure 1(a) and (b), the grinding operations generated tensile $\sigma_{\|}$but compressive $\sigma_{\perp}$ in the surface layer for both austenitic 304L and ferritic 4509. The tensile $\sigma_{\|}$was highest in the ground surface and dropped rapidly to compression in the subsurface. The compressive $\sigma_{\perp}$ showed a relative low value in the surface and increased rapidly to reach a peak value in the subsurface. The tensile surface residual stresses were higher for the austenite 304L than ferrite 4509. However, grinding induced residual stresses showed different features in the austenitic and ferritic phases in the duplex 2304. In the austenitic phase (Figure 1(c1)), tensile $\sigma_{\|}$and compressive $\sigma_{\perp}$ were observed; the measured tensile $\sigma_{\|}$ dropped gradually from the surface to the subsurface while the compressive stress showed a peak value in $\sigma_{\perp}$ the subsurface region. This is very similar to the trend seen for the austenitic 304L steel. In the ferritic phase (Figure 1(c2)), except for the $\sigma_{\|}$for grinding using $60 \#$ abrasive in the surface layer, both $\sigma_{\|}$and $\sigma_{\perp}$ were compressive with a subsurface peak value and $\sigma_{\perp}$ was more compressive than $\sigma_{\|}$. On the macroscopic scale (Figure 1(c3)), similar trends were observed to the single phase materials. For all the results shown in Figure 1, grinding with $60 \#$ grit size abrasive generated higher residual stresses in both surface and subsurface region and a higher penetration depth compared with grinding using 180\# as final surface finish.

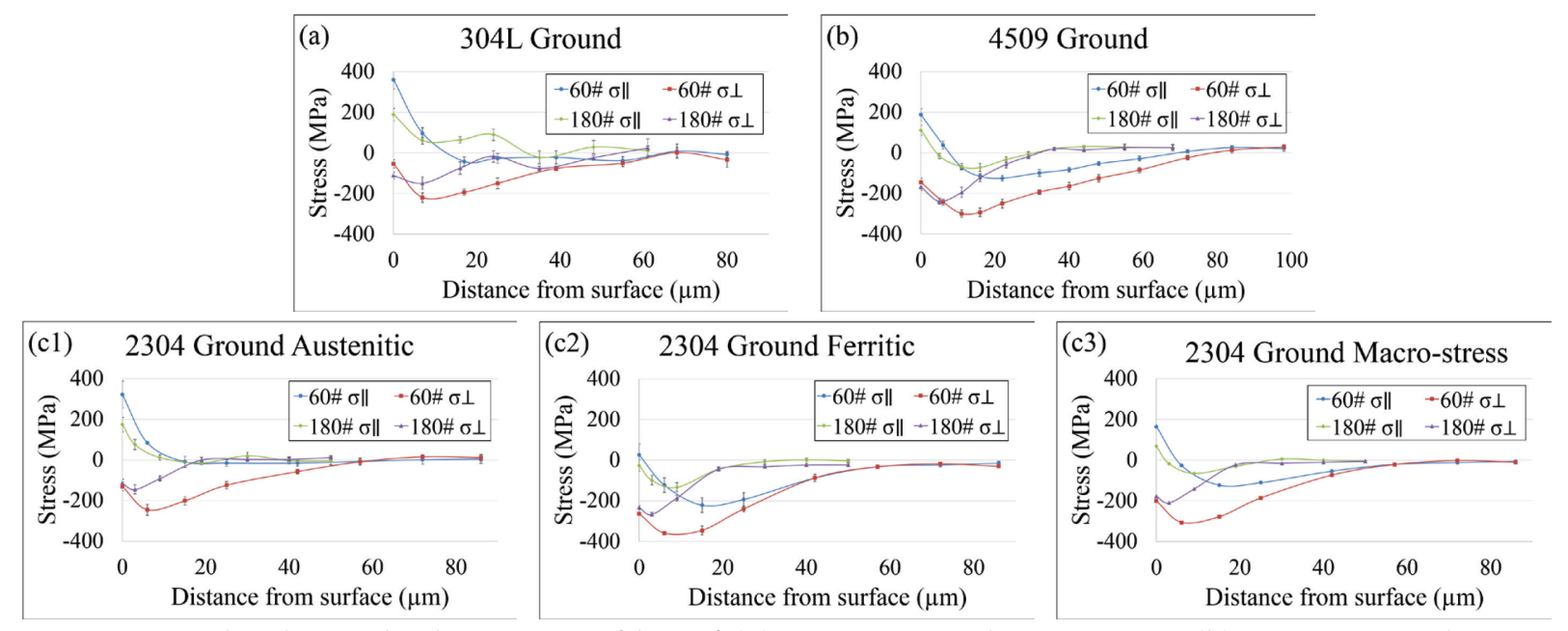

Figure 1 In-depth residual stress profiles of (a) 304L ground specimens, (b) 4509 ground specimens, and (c) 2304 ground specimens

Residual stress in grinding is caused by the combination of thermal and mechanical effects. During grinding, heat is generated in the surface layer of the workpiece material, thus a temperature gradient is formed from surface to the bulk. Since the bulk material hinders contraction of the surface layer during the cooling period, surface tension can be generated both along and transverse to the grinding direction [5]. However, an anisotropic surface residual stress field with tensile $\sigma_{\|}$and compressive $\sigma_{\perp}$ was observed in $304 \mathrm{~L}, 4509$ and the macro-stresses of 2304, indicating that the mechanical effect, i.e. anisotropic plastic deformation, is more dominant than the thermal effect in this study. During grinding, the surface layer experienced overall compressive plastic deformation in the grinding direction and tensile deformation in the transverse direction, thus the constraint by the material beneath the surface layer resulted in surface tensile $\sigma_{\|}$but compressive $\sigma_{\perp}$ after the grinding 
zone moved away [6]. Higher tensile residual stresses were measured from surface to subsurface in 304L than in 4509 in both directions, even though same grinding parameters were used. The lower thermal conductivity of the austenitic stainless steel is probably the main contributory factor. In addition, the in-depth residual stress profiles showed different trends for the ferritic 4509 and the ferritic phase of the duplex 2304. This is attributable to the complicated interaction between the austenitic and ferritic phases in the duplex material during grinding due to their difference in both thermal and mechanical properties. For all three materials, using smaller grit size abrasive (180\#) introduced lower deformation in both surface and subsurface layers, thus lower residual stress with lower penetration depth were observed in both directions.
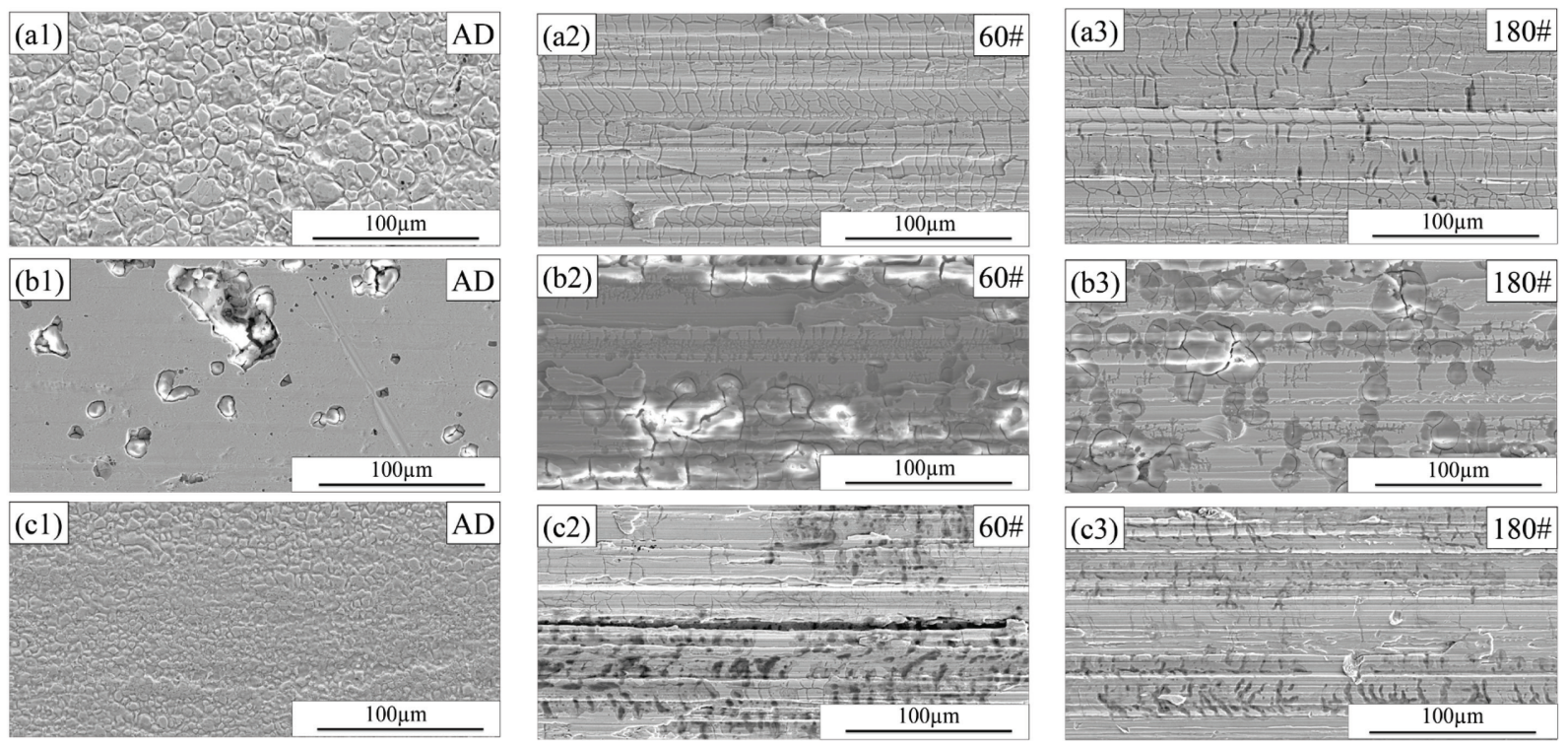

Figure 2 Surface morphology of as-delivered (AD) material, ground 60\# and 180\# specimens after exposure without external loading: (a) austenite 304L, (b) ferrite 4509, (c) duplex 2304
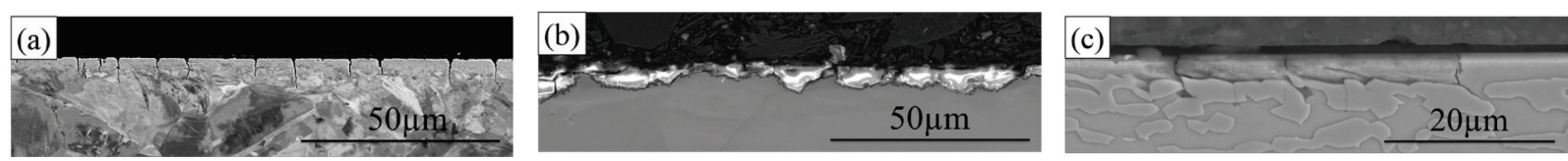

Figure 3 Cross-section microstructure of ground 60\# specimens sectioned parallel to the grinding direction after exposure without external loading: (a) austenite 304L, (b) ferrite 4509, (c) duplex 2304

Surface morphology and cross-section microstructure were investigated after corrosion testing for all ground specimens, selected images of the three types of materials are shown in Figure 2 and Figure 3. Extensive branched micro-cracks were present in the ground surfaces of both the austenite 304L and the duplex 2304 in spite of the absence of external loading. It should be noted that no such cracking was observed on the as-delivered surface. Both the surface and cross-section investigations showed the micro-cracks were primarily oriented perpendicular to the grinding marks; while in the parallel direction, much fewer micro-cracks with lower penetration depth were observed. This correlates to the high levels of tensile stresses measured parallel to the grinding direction in the surface layer. The results strongly indicate that tensile residual stress in the ground surface makes both materials susceptible to SCC in chloride existing environment even in the absence of any external loading, while compressive residual stress transverse to the grinding direction can retard cracking. For the austenitic $304 \mathrm{~L}$, the majority of the micro-cracks arrested at the depth where the 
residual stress profiles shifted from high tensile level to low or no tensile residual stresses, indicating that a threshold tensile stress is required to initiate cracks and sustain their propagation in the boiling $\mathrm{MgCl}_{2}$ solution. Tensile $\sigma_{\|}$in austenitic phase and compressive $\sigma_{\|}$in ferritic phase were measured for ground surfaces of 2304, however, micro-cracks were observed to initiate and propagate in both phases. The macroscopic residual tensile stress thus seems to play a more dominant role than the single phase stresses. The penetration depth of the micro-cracks correlated to the position where the macro-stress shifted from tension to compression, and cracks also tended to be arrested at phase boundaries. For both materials, less micro-cracks with lower penetration appeared by using smaller grit size (180\#) abrasives after exposure. The penetration depth of micro-cracks in duplex 2304 was smaller than that for the austenitic grade, even though the same grinding and exposure conditions were used. In the case of the ferritic 4509 a large number of pits, with varied size and filled with corrosion products, were observed after exposure. The extensive pitting may reflect the lower alloying content of this steel. Many more pits were observed on the ground surface than the asdelivered material; in addition, pitting was more severe for the ground 60\# than 180\# specimens, suggesting that the roughness, topography, deformation and residual stress of the surface layer contributes to an increasing pitting susceptibility. Cross-sectional investigations showed the pits were largely limited to the deformed surface and subsurface layers, and that some cracks appeared to have initiated from the pits. It is suggested that the extensive pitting on 4509 has to a large extent suppressed stress corrosion cracking, even though some cracks can emanate from pits.

Measured surface stresses along the grinding direction of all ground specimens before and after exposure without external loading are plotted and compared in Figure 4. As shown in the figure, for all the specimens, the grinding induced surface tensile $\sigma_{\|}$were observed to be reduced after exposure. For all the three materials, grinding by $60 \#$ abrasive grit size generated much higher tensile $\sigma_{\|}$than 180\# in the ground surface; however, measured surface stresses showed similar values for both grinding conditions after exposure. The micro-cracks in austenitic 304L and duplex 2304 and the pits in 4509 are proposed as the main factors that caused surface stress release after exposure.
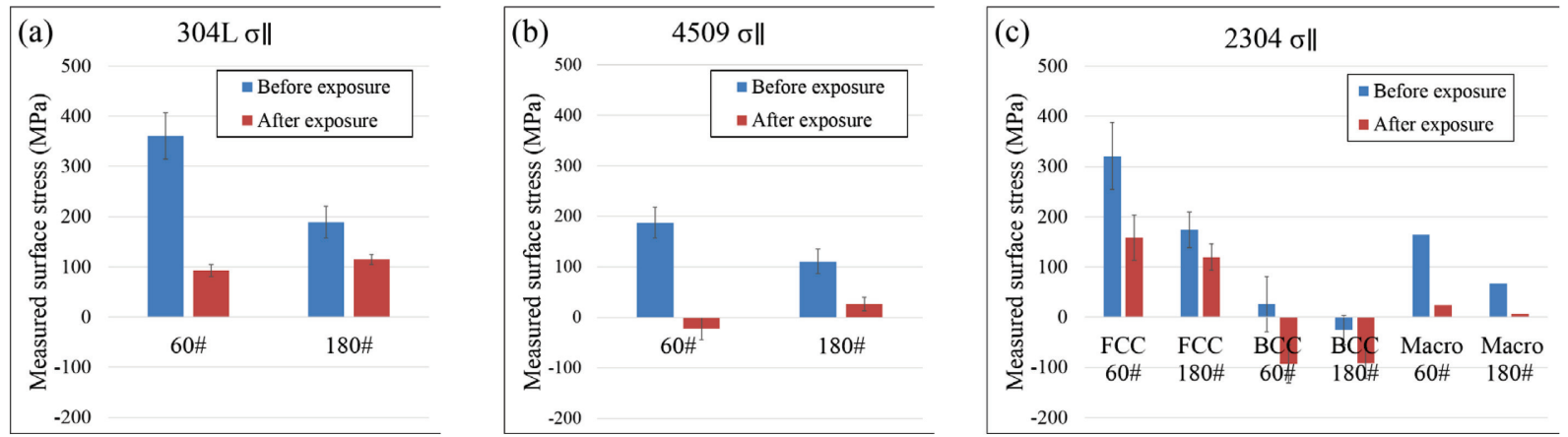

Figure 4 Surface stress of ground specimens parallel to grinding direction before and after testing in $\mathrm{MgCl}_{2}$ solution: (a) austenite 304L, (b) ferrite 4509, (c) duplex 2304

\section{Conclusions}

Grinding generated surface macroscopic tensile residual stresses along the grinding direction and compressive residual stresses perpendicular to the grinding direction for the austenitic 304L, ferritic 4509 and duplex 2304 stainless steels. In the subsurface region, compressive stresses were present in both directions. Residual stresses were more tensile for the austenitic phase in the duplex steel than the ferritic phase. Results indicate that anisotropic mechanical effects dominant over isotropic thermal effects for the grinding operation in this study. Abrasive grit size had a significant influence on both the level and the penetration depth of residual stress. 
Grinding induced surface tensile residual stresses caused micro-cracks to initiate from the surface during exposure to boiling magnesium chloride solution even in the absence of external loading for both 304L and 2304. The cracks arrested when reaching the depth with low or no tensile stresses. For the duplex 2304, cracks were present in both phases but tended to stop at phase boundaries. Less cracking was seen in the ferritic 4509. This was attributed to the extensive pitting which is a consequence of the lower alloying level of this steel.

The formation of micro-cracks or pits was proposed as the main factor contributing the reduction of surface stresses after exposure in the magnesium chloride solution.

\section{Acknowledgement}

This work is financially supported by Outokumpu Stainless Research Foundation, Region Dalarna, Region Gävleborg, Länsstyrelsen Gävleborg, Jernkontoret, Sandviken kommun and Högskolan Dalarna within the Steel Industry Graduate School.

\section{References}

[1] Outokumpu, Handbook of Stainless Steels, Outokumpu Oyj, Finland, 2013.

[2] D. Jones, Principles and prevention of corrosion, Pearson Education (US), 1996.

[3] Outokumpu, Corrosion Handbook, Outokumpu Oyj, Finland, 2015.

[4] E. Johansson and T. Prosek, "Stress corrosion cracking properties of UNS S32101 - a new duplex stainless steel with low nickel content," in Corrosion 2007 Conference \& Expo, 2007.

[5] J. Lu, K. Luo, D. Yang, X. Cheng, J. Hu, F. Dai, H. Qi, L. Zhang, J. Zhong, Q. Wang and Y. Zhang, "Effects of laser peening on stress corrosion cracking (SCC) of ANSI 304 austenitic stainless steel," Corrosion Science, vol. 60, pp. 145-152, 2012.

http://dx.doi.org/10.1016/j.corsci.2012.03.044

[6] K. Lyon, T. Marrow and S. Lyon, "Influence of milling on the development of stress corrosion cracks in austenitic stainless steel," Journal of Materials Processing Technology, vol. 218, pp. 32-37, 2015. http://dx.doi.org/10.1016/j.jmatprotec.2014.11.038

[7] N. Zhou, R. L. Peng and R. Pettersson, "Surface Integrity of 2304 Duplex Stainless Steel After Different Grinding Operations," Journal of Materials Processing Technology, vol. 229, pp. 294304, 2016. http://dx.doi.org/10.1016/j.jmatprotec.2015.09.031

[8] N. Zhou, R. Pettersson, R. L. Peng and M. Schönning, "Effect of Surface Grinding on Chloride Induced SCC of 304L," Materials Science and Engineering: A, vol. 658, pp. 50-59, 2016. http://dx.doi.org/10.1016/j.msea.2016.01.078

[9] I. Noyan and J. Cohen, Residual Stress Measurement by Diffraction and Interpretation, Springer, 1987.

[10] J. Davim, Surface intergrity in machining, Springer London Ltd, 2010. http://dx.doi.org/10.1007/978-1-84882-874-2

[11] G. Q. Guo, Z. Q. Liu, X. J. Cai, Q. L. An and M. Chen, "Investigation of Surface Integrity in Conventional Grinding of Ti-6Al-4V," Advanced Materials Research, Vols. 126-128, pp. 899904, 2010. http://dx.doi.org/10.4028/www.scientific.net/AMR.126-128.899

[12] V. Hauk, Structural and Residual Stress Analysis by Nondestructive Methods, Elsevier Science, 1997. 